\title{
Left Atrial Size Contribution to the Predictive Capacity of Two Scores for Atrial Fibrillation in the Postoperative Period of Cardiac Surgeries
}

\author{
Natália Aline da Silva ${ }^{1,2}$ and Rita de Cássia Gengo e Silva Butcher ${ }^{3}$ \\ Faculdade de Medicina da Universidade de São Paulo,' São Paulo, SP - Brazil \\ Escola de Enfermagem da Universidade de São Paulo, ${ }^{2}$ São Paulo, SP - Brazil \\ Programa de Pós-graduação em Enfermagem na Saúde do Adulto da Escola de enfermagem da Universidade de São Paulo, ${ }^{3}$ São Paulo, SP - Brazil
}

\section{Abstract}

Background: Postoperative atrial fibrillation (POAF) is a common complication associated with undesirable outcomes; hence, the provision of appropriate tools is important to help identify patients at risk.

Objectives: To evaluate the predictive capacity of the $\mathrm{CHADS}_{2}$ and $\mathrm{CHA}_{2} \mathrm{DS}_{2}-\mathrm{VASc}$ scores, alone and combined with left atrial (LA) size, for the onset of POAF in patients undergoing coronary artery bypass grafting and/or valvular surgery.

Methods: We performed a retrospective cohort study on 144 patients. A decision tree was used to identify the cut-off values of the $\mathrm{CHADS}_{2}$ and $\mathrm{CHA}_{2} \mathrm{DS}_{2}-\mathrm{VASc}$ scores and LA size in order to calculate sensitivity, specificity, predictivevalue positive (PVP), and predictive-value negative (PVN), in addition to regression models. The receiver operating characteristic (ROC) curve was used to estimate the accuracy of the models. The level of significance adopted was $5 \%$.

Results: Patients who developed POAF were older $(\mathrm{p}=0.050)$, had reduced left ventricular ejection fraction $(p=0.045)$, longer hospital length of stay $(p=0,018)$, but their mean $\mathrm{CHADS}_{2}(\mathrm{p}=0.077)$ and $\mathrm{CHA}_{2} \mathrm{DS}_{2}-\mathrm{VASc}$ $(\mathrm{p}=0.109)$ scores were similar to those of patients with no arrhythmia. LA size improved the predictive capacity of the $\mathrm{CHADS}_{2}$ score, in terms of specificity and PVP, and of the $\mathrm{CHA}_{2} \mathrm{DS}_{2}-\mathrm{VASc}$ score, in terms of sensitivity and PVN. However, the $\mathrm{CHADS}_{2}(\mathrm{OR}=1.198 ; \mathrm{CI} 95 \%=0.859-1.156)$ and $\mathrm{CHA}_{2} \mathrm{DS}_{2}-\mathrm{VASc}(\mathrm{OR}=1.047 ; \mathrm{CI} 95 \%=0.784-$ $1.401)$ scores were not predictors of POAF, either alone or in combination with LA size $(\mathrm{OR}=1.163 ; \mathrm{CI} 95 \%=0.829$ 1.648 and $\mathrm{OR}=1.065 ; \mathrm{CI} 95 \%=0.795-1.433)$.

Conclusion: The $\mathrm{CHADS}_{2}$ and $\mathrm{CHA}_{2} \mathrm{DS}_{2}-\mathrm{VASc}$ scores alone or in combination with LA size did not show good predictive capacity for POAF. (Int J Cardiovasc Sci. 2019;32(6):585-593)

Keywords: Atrial Fibrillation; Arrhythmias, Cardiac/ complications; Postoperative Complications; Cardiac Surgical Procedures.

\section{Introduction}

Atrial fibrillation (AF) is cardiac arrhythmia resulting from grossly disorganized atrial electrical activity, due to multiple and continuous intra-atrial reentrant circuits, characterized by impaired atrial contraction, followed by absent atrial systole. ${ }^{1}$ Certain pathological heart conditions, such as those evolving with structural changes, or surgical manipulation of the organ, may increase the risk of developing AF. ${ }^{2}$ Arrhythmia occurs in about $30 \%$ of patients in the postoperative of coronary artery bypass graft surgery and in up to $60 \%$ of postoperative patients submitted to concomitant valvular surgery. ${ }^{3,4}$

The consequences of AF, especially when it is irreversible, are clearly associated with the risk of thromboembolic phenomena and mortality, affecting $11 \%$ of the elderly population, up to 30 days after the 
diagnosis. ${ }^{5}$ In addition, cognitive changes, heart failure and worsened quality of life have been reported. ${ }^{6,7}$

Having tools for predicting the risk of developing AF in the postoperative period of cardiac surgery (POAF) may contribute to the implementation of measures designed to prevent and improve the monitoring of patients at risk. Different models have been tested to that end, ${ }^{4,8,9}$ such as the $\mathrm{CHADS}_{2}$ and $\mathrm{CHA}_{2} \mathrm{DS}_{2}$-VASc scores. . $^{9-11}$

Although these scores have been originally developed to assess the risk of thromboembolism in patients with $\mathrm{AF}$, their items include risk factors for the onset of arrhythmia itself. ${ }^{1,2,12}$ However, the results of studies that have evaluated the predictive capacity of the $\mathrm{CHADS}_{2}$ and $\mathrm{CHA}_{2} \mathrm{DS}_{2}-\mathrm{VASc}$ scores in relation to POAF are controversial. ${ }^{9,10,13}$

Recently, a study demonstrated that left atrial (LA) size was the best variable to discriminate between patients with or without POAF. ${ }^{14}$ To our knowledge, no study has assessed the contribution of LA size evaluation to the predictive ability of those scores. The objectives of this study were to verify the predictive capacity of the $\mathrm{CHADS}_{2}$ and $\mathrm{CHA}_{2} \mathrm{DS}_{2}$-VASc scores for the onset of POAF in patients submitted to coronary artery bypass grafting and/or valvular surgery; and to assess the contribution of LA size to the predictive capacity of these scores.

\section{Methods}

This is a retrospective cohort study. Data were collected in the period from June 2017 to October 2017 at the Heart Institute of the Clinics Hospital of the School of Medicine of the University of São Paulo (INCORHC-FMUSP).

\section{Population of interest and sample collection}

The population of interest for this study included patients submitted to coronary artery bypass grafting and / or valvular surgery, either alone or in combination, during the year 2015.

The sample of the study was determined as 144 patients, considering an incidence of POAF as high as $50 \%$, number of surgical procedures performed in 2015 at the institution, area of data collection and assuming type I error of $5 \%$. We included medical records of patients aged 18 years or more, who had undergone coronary artery bypass grafting and/or valvular surgery. We excluded the medical records of patients diagnosed with pre- or intraoperative $\mathrm{AF}$, from those who had undergone other types of associated surgeries or whose medical records were lacking information needed for the development of this study.

We located medical records for 1,225 individuals in the hospital's electronic records system. Out of these, 234 were excluded (188 belonged to patients with a diagnosis of pre-operative AF and 46, to patients who had undergone other surgical procedures concomitantly). The other medical records $(\mathrm{n}=991)$ were revised and divided into two groups: with POAF $(\mathrm{n}=148)$ and without POAF $(\mathrm{n}=843)$ and, subsequently, they received codes which were used to draw the final sample.

In order to minimize the interference of external factors in this study, six medical records were chosen from the group with $\mathrm{POAF}$ and six from the group without POAF every month, for a total of twelve per month. The draw was carried out electronically (sorteador.com). Therefore, each group was composed of 72 patient records.

The study was conducted in accordance with the principles of the Declaration of Helsinki and approved by the Ethics Committee in Research (approval number 1.957.400). The need for informed consent form was waived because all data were obtained from the patient records.

\section{Variables}

The clinical and demographic variables analyzed were: age, sex, skin color, smoking, $\mathrm{CHADS}_{2}$ and $\mathrm{CHA}_{2} \mathrm{DS}_{2}$-VASc scores, preoperative echocardiographic data (left atrial size, left ventricle diastolic diameter and left ventricular ejection fraction), use of continuous medication in the preoperative period, intraoperative data (type of cardiac surgery, time of anesthesia, use of extracorporeal circulation (ECC) and the time of ECC); and postoperative data (POAF diagnosis, immediate postoperative laboratory tests, in the immediate postoperative, length of stay and death). Postoperative and POAF data were analyzed during the whole period of hospitalization. The onset of arrhythmia in the postoperative period, registered in electronic medical record system, was considered an episode of POAF.

\section{$\mathrm{CHADS}_{2}$ and $\mathrm{CHA}_{2} \mathrm{DS}_{2}-\mathrm{VASc}$}

The $\mathrm{CHADS}_{2}$ score was proposed after scientific evidence suggest that certain factors other than $\mathrm{AF}$ contributed to the onset of thromboembolic phenomena in these patients. ${ }^{5}$ The identification of the major factors associated with 
thromboembolism culminated with the publication in 2001 of this risk score. ${ }^{12}$ The main purpose was to identify outpatients at risk who could benefit from treatment with oral anticoagulants. $\mathrm{CHADS}_{2}$, however, identifies highrisk patients. Nevertheless, due to the inherent risks of arrhythmia itself, as well as to the particular contribution of other risk factors for the onset of thromboembolism, the $\mathrm{CHA}_{2} \mathrm{DS}_{2}-\mathrm{VASc}$ score was proposed to identify real low risk patients who did not need anticoagulation. ${ }^{5}$

The $\mathrm{CHADS}_{2}$ score consists of four items that count for one point each (congestive heart failure, age $>75$ years and diabetes mellitus) and one item that counts as 2 points (stroke and transient ischemic attack). The total score ranges from zero to six points. Originally, the higher the score, the higher the risk of thromboembolic phenomena. ${ }^{12}$

The $\mathrm{CHA}_{2} \mathrm{DS}_{2}-\mathrm{VASc}$ score includes three additional factors (vascular disease, age 65-74 years and female gender); each additional factor counts as 1 point, while an age $>75$ years was upgraded to two points. The total score ranges from zero to nine. Originally, the higher the score, the higher the risk of thromboembolic phenomena. ${ }^{15}$

\section{Data analysis}

Categorical variables were described by absolute and relative frequencies, and analyzed using Chi-square test and Fisher's exact test. Quantitative variables were described by using central tendency and dispersion measurements and Student's t-test. The cut-off values of the $\mathrm{CHADS}_{2}$ and $\mathrm{CHA}_{2} \mathrm{DS}_{2}-\mathrm{VASc}$ sores and LA size were determined via decision tree. The predictive capacity of the scores alone and in combination with the LA size was determined by sensitivity, specificity, positive predictive value (PPV), negative predictive value (NPV) and logistic regression models. The assumption of normality of the scores was not tested, because they are discrete variables. The adjustment of the models was evaluated by the area under (AUC) the Receiver Operating Characteristic (ROC) curve. All analyses were performed using the statistical software R 3.4.3. The significance level adopted was $5 \%$.

\section{Results}

We selected 144 medical records of patients submitted to coronary artery bypass grafting and/or valvular surgery in 2015, half of whom had developed POAF. The demographic and clinical characteristics of interest, registered in the preoperative period, are described in Table 1.

Although table 1 does not show statistically significant difference between patients with and without POAF, in relation to age, it is possible to consider that, clinically,

Table 1 - Demographic and clinical characteristics recorded in the postoperative period of patients with $(n=72)$ and without $(n=72)$ postoperative atrial fibrillation

\begin{tabular}{lccc}
\hline & With POAF & Without POAF & p-value \\
\hline Age, in years, mean (SD) & $65.8(10.7)$ & $61.8(13.3)$ & $0.050^{*}$ \\
Male gender, n(\%) & $44(61.1)$ & $47(65.3)$ & $0.604+$ \\
Skin color, n(\%) & & & $0.678+$ \\
$\quad$ White & $61(84.7)$ & $9(12.5)$ & \\
$\quad 11(15.3)$ & $2(2.8)$ & $12(16.6)$ & $0.478+$ \\
$\quad$ & & & \\
$\quad$ Other & $9(12.5)$ & $41.3(6.3)$ & $0.059^{*}$ \\
Active smoking, n(\%) & & $52.1(7.0)$ & $0.359^{*}$ \\
Preoperative echocardiographic data & $43.4(6.6)$ & $59.2(10.6)$ & $0.045^{*}$ \\
Left atrial size, in mm, mean (SD) & $53.3(7.7)$ & $55.3(12.4)$ & \\
LVDd, mm, mean (SD) & & \\
LVEF \%, mean (SD) & & & \\
\hline
\end{tabular}

POAF: postoperative atrial fibrillation; SD: standard deviation; LVDd: left ventricular diastolic diameter; $\left.{ }^{*}\right)$ Student's $t$-test; $(+)$ Pearson's chi-square test. 
the age is associated with the onset of arrhythmia in the postoperative period $(\mathrm{p}=0.050)$.

In relation to medication taken on a regular basis at home, the use of different classes was observed, among which, antihypertensives, antiarrhythmics, statins, antiplatelet agents, anticoagulants and diuretics. However, we only found statistically significant difference between patients with or without POAF in relation to the use of digitalis ( $0 \%, \mathrm{n}=0$ vs $6.9 \%, \mathrm{n}=5$, respectively; $\mathrm{p}=0.026)$.

Laboratory tests results conducted in the preoperative period were not analyzed because they were not available for many patients. Table 2 describes the minimum and maximum values observed in laboratory tests results collected in the first 24 hours after surgery.
The other intra- and postoperative data of interest for this study are described in Table 3.

The $\mathrm{CHADS}_{2}$ mean scores for patients with and without POAF were, respectively, $1.82+1.05$ and $1.49+1.18(\mathrm{p}=0.077)$. The $\mathrm{CHA}_{2} \mathrm{DS}_{2} \mathrm{VASc}$ mean scores, on the other hand, were, $3.38+1.53$ and $2.96+1.56$, in this sequence $(p=0.109)$. In order to evaluate the predictive capacity of these scores, alone or combined with LA size, we established the cut-off point of each score to better identify the patients who developed POAF (Chart 1).

Table 4 describes the predictive capacity of these scores, either alone or associated with LA size, to determine the onset of POAF.

Table 2 - Minimum and maximum values observed in the laboratory tests results conducted in the immediate postoperative period of patients with $(n=72)$ and without $(n=72)$ postoperative atrial fibrillation

\begin{tabular}{|c|c|c|c|c|}
\hline & Minimum & p-value* & Maximum & p-value ${ }^{*}$ \\
\hline \multicolumn{5}{|c|}{ Magnesium, mEq/L, mean (SD) } \\
\hline With AF & $1.5(0.4)$ & \multirow{2}{*}{0.248} & $2.1(0.5)$ & \multirow{2}{*}{0.950} \\
\hline Without AF & $1.6(0.4)$ & & $2.1(0.6)$ & \\
\hline \multicolumn{5}{|c|}{ Potassium, $\mathrm{mEq} / \mathrm{L}$, mean (SD) } \\
\hline With AF & $3.8(0.4)$ & \multirow[b]{2}{*}{0.251} & $4.4(0.5)$ & \multirow[b]{2}{*}{0.780} \\
\hline Without AF & $3.9(0.9)$ & & $4.4(0.9)$ & \\
\hline \multicolumn{5}{|c|}{ Sodium, mEq/L, mean (SD) } \\
\hline With AF & $135.5(3.2)$ & \multirow{2}{*}{0.194} & $138.9(3.7)$ & \multirow{2}{*}{0.404} \\
\hline Without FA & $136.6(6.1)$ & & $139.6(5.9)$ & \\
\hline \multicolumn{5}{|c|}{ Calcium, mEq/L, mean (SD) } \\
\hline With AF & $1.15(0.06)$ & \multirow[b]{2}{*}{0.406} & $1.25(0.1)$ & \multirow[b]{2}{*}{0.984} \\
\hline Without AF & $1.16(0.06)$ & & $1.25(0.1)$ & \\
\hline \multicolumn{5}{|c|}{ CRP, mEq/L, mean (SD) } \\
\hline With AF & $8.4(11.0)$ & \multirow[b]{2}{*}{0.019} & $111.1(69.7)$ & \multirow[b]{2}{*}{0.099} \\
\hline Without AF & $16.8(27.4)$ & & $92.6(64.1)$ & \\
\hline \multicolumn{5}{|c|}{ Creatinine, $\mathrm{mEq} / \mathrm{L}$, mean (SD) } \\
\hline With AF & $1.0(0.4)$ & \multirow{2}{*}{0.277} & $1.4(0.6)$ & \multirow{2}{*}{0.601} \\
\hline Without AF & $1.3(1.6)$ & & $1.6(1.7)$ & \\
\hline \multicolumn{5}{|c|}{ Urea, mEq/L, mean (SD) } \\
\hline With AF & $38.1(16.0)$ & \multirow[b]{2}{*}{0.840} & $48.0(22.1)$ & \multirow[b]{2}{*}{0.210} \\
\hline Without AF & $38.7(18.5)$ & & 43.6 (19.8) & \\
\hline
\end{tabular}


Table 3 - Intra- and postoperative variables of patients with $(n=72)$ and without $(n=72)$ postoperative atrial fibrillation

\begin{tabular}{|c|c|c|c|}
\hline & $\begin{array}{l}\text { With POAF } \\
\quad(n=72)\end{array}$ & $\begin{array}{l}\text { Without POAF } \\
\quad(n=72)\end{array}$ & p-value \\
\hline \multicolumn{4}{|l|}{ Type of surgery, n(\%) } \\
\hline Coronary artery bypass grafting & $36(50.0)$ & $35(48.7)$ & \\
\hline Valvular surgery & $32(44.4)$ & $32(44.4)$ & $1.000^{*}$ \\
\hline Both & $4(5.6)$ & $5(6.9)$ & \\
\hline $\mathrm{ECC}, \mathrm{n}(\%)$ & $68(94.4)$ & $65(90.2)$ & $0.346+$ \\
\hline Time of ECC, in hours, mean (SD) & $1.4(0.5)$ & $1.5(0.8)$ & $0.726 \ddagger$ \\
\hline Time of anesthesia, in hours, mean (SD) & $7.2(1.3)$ & $7.3(1.8)$ & $0.640 \neq$ \\
\hline Use of VAD in IPO, $\mathrm{n}(\%)$ & $71(98.6)$ & $72(100.0)$ & $1.000^{*}$ \\
\hline Total length of stay, in days, mean (SD) & $17.8(13.3)$ & $12.6(12.4)$ & $0.018 \ddagger$ \\
\hline Death, $\mathrm{n}(\%)$ & $3(4.1)$ & $10(13.8)$ & $0.042+$ \\
\hline
\end{tabular}

POAF: postoperative atrial fibrillation; SD: standard deviation; ECC: extracorporeal circulation; IPO: immediate postoperative period; VAD: vasoactive drug; $\left(^{*}\right)$ Fisher's exact test; $(+)$ Pearson's chi-squared test; $(\ddagger)$ Student's $t$-test.
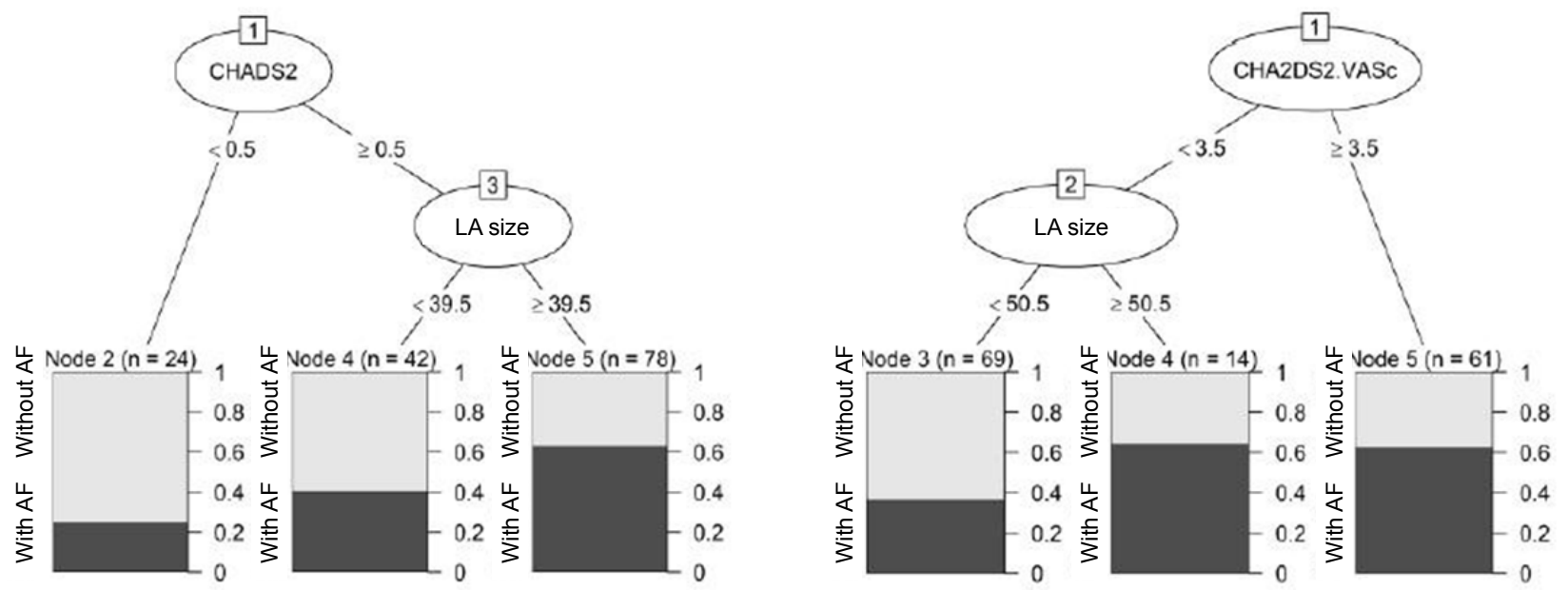

Chart 1 - Cut-off values for discrimination of patients with and without postoperative atrial fibrillation according to the CHADS $_{2}$ (A) and $\mathrm{CHA}_{2} \mathrm{DS}_{2}-\mathrm{VASc}(\mathrm{B})$ scores and left atrial size.

Tables 5 and 6 show logistic regression models of the $\mathrm{CHADS}_{2}$ and $\mathrm{CHA}_{2} \mathrm{DS}_{2}$ VASc scores alone and in association with left atrial size.

Chart 2 shows the ROC curve area for the scores alone or in association with LA size.

\section{Discussion}

The present study described the prediction capacity of the $\mathrm{CHADS}_{2}$ and $\mathrm{CHA}_{2} \mathrm{DS}_{2}$ VASc scores, alone or in association with LA size, to determine the onset of POAF 
Table 4 - Sensitivity, specificity and positive and negative predictive values of $\mathrm{CHADS}_{2}$ and $\mathrm{CHA}_{2} \mathrm{DS}_{2} \mathrm{VASc} \mathrm{scores}_{\text {, }}$ alone or in association with LA size, to determine atrial fibrillation following coronary artery bypass grafting and/or valvular surgery

\begin{tabular}{|c|c|c|c|c|}
\hline & $\mathrm{CHADS}_{2}>0.5$ & $\mathrm{CHA}_{2} \mathrm{DS}_{2} \mathrm{VASc}<3.5$ & $\begin{array}{c}\mathrm{CHADS}_{2}>0.5 \text { and LA } \\
>39.5 \mathrm{~mm}\end{array}$ & $\begin{array}{c}\mathrm{CHA}_{2} \mathrm{DS}_{2} \text { VASc }<3.5 \\
\text { and } \mathrm{LA}>50.5 \mathrm{~mm}\end{array}$ \\
\hline Sensitivity & 91.7 & 52.8 & 68.1 & 65.3 \\
\hline Specificity & 25.0 & 68.1 & 59.7 & 61.1 \\
\hline Predictive value positive & 55.0 & 62.3 & 62.8 & 62.7 \\
\hline Predicitive value negative & 75.0 & 59.0 & 65.1 & 63.8 \\
\hline
\end{tabular}

Table 5 - Logistic regression model of the $\mathrm{CHADS}_{2}$ score alone (Model 1) and in association with left atrial size (Model 2) for predicting the onset of postoperative atrial fibrillation following coronary artery bypass grafting and/or valvular surgery

\begin{tabular}{llccc}
\hline & & Odds ratio (CI 95\%) & p-valor & AUC (CI 95\%) \\
\hline Model 1 & CHADS $_{2}$ & $1.198(0.859-1.156)$ & 0.291 & $0.611(0.518-0.714)$ \\
Model 2 & CHADS $_{2}$ & $1.163(0.829-1.648)$ & 0.387 & $0.643(0.552-0.733)$ \\
& LA size & $1.049(0.995-1.107)$ & 0.078 & \\
\hline
\end{tabular}

AUC: area under the curve; CI: confidence interval.

Table 6 - Logistic regression model of the $\mathrm{CHA}_{2} \mathrm{DS}_{2}$ VASc score alone (Model 3) and in association with left atrial size (Model 4) for predicting the onset of postoperative atrial fibrillation following coronary artery bypass grafting and/or valvular surgery

\begin{tabular}{lcccc}
\hline & & Odds ratio (IC 95\%) & p-valor & AUC (CI 95\%) \\
\hline \multirow{2}{*}{ Model 3 } & $\mathrm{CHA}_{2} \mathrm{DS}_{2}$ VASc & $1.047(0.784-1.401)$ & 0.754 & $0.590(0.497-0.683)$ \\
Model 4 & $\mathrm{CHA}_{2} \mathrm{DS}_{2} \mathrm{VASc}$ & $1.065(0.795-1.433)$ & 0.673 & $0.633(0.542-0.724)$ \\
& LA size & $1.052(0.999-1.110)$ & 0.061 & \\
\hline
\end{tabular}

AUC: area under the curve; CI: confidence interval.

in patients undergoing myocardial revascularization surgery and / or valvular surgery. As far as we know, no other study had added the contribution of left atrial size to the prediction capacity of those scores. Having tools that allows us to predict the risk of POAF in an easy and reliable way is important because it could help identify patients at risk, who would benefit from more careful monitoring in the postoperative period, as well as, for the institution of prevention measures.

Patients with POAF were older compared to those who did not develop arrhythmia. Advanced age is, admittedly, a major risk factor for AF in patients in general ${ }^{16,17}$ and in those undergoing cardiac surgery. ${ }^{18,19}$ In fact, population aging, especially in emerging countries, 


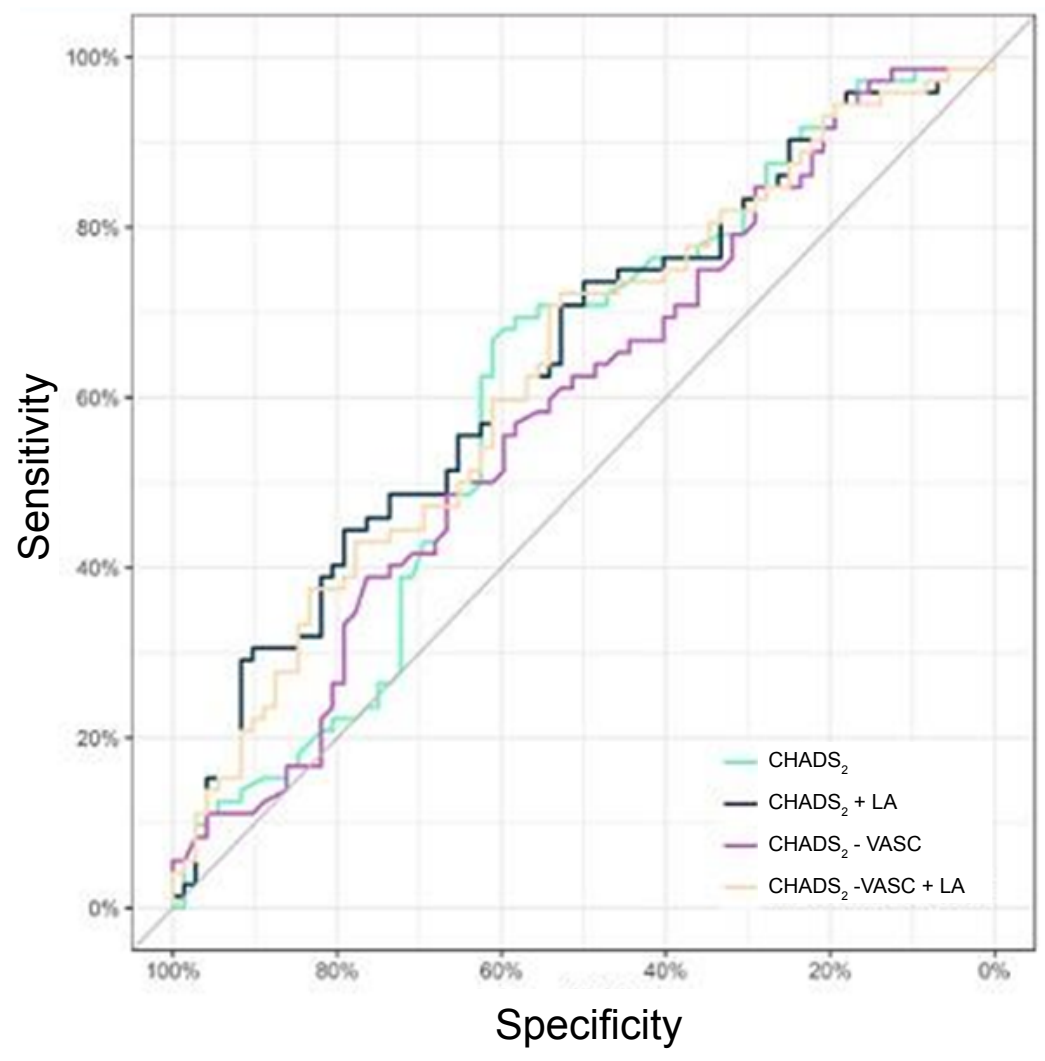

Chart 2 - Predictive ability of models constituted by the scores alone or in association with left atrial size to predict new-onset atrial fibrillation after coronary artery bypass graft surgery and/or valvular surgery.

will play an important role in changing the incidence of this type of arrhythmia in the general population, as well as in patients undergoing cardiac surgery. ${ }^{5}$

The mean ejection fraction in both groups was considered within normal limits, although LA size was slightly increased in both groups. ${ }^{20}$ When AF is addressed in the context of heart failure, arrhythmia is more frequent in patients with normal ejection fraction, due to volume overload and pressured atrial chambers. ${ }^{21}$ Atrial remodeling, caused by a structural rearrangement of myocardial fibers, is directly linked with the presence of AF. ${ }^{21}$ Other authors have reported that LA size is associated with the occurrence of arrhythmia ${ }^{2,4,9,22}$ and seems to be the best discriminant between postoperative patients who developed POAF and those who did not. ${ }^{14}$ Considering the important role played by the LA in the physiopathology of $\mathrm{AF}$, and the results of previous studies, we decided to test the predictive capacity of the scores alone and combined with this measure, even though no difference was observed between the groups with and without AF in relation to the size of this heart chamber. This will be further discussed below.

Regarding the use of continuous medication, comparison between the groups with and without AF showed that only the use of digitalis was different. Although this drug was prescribed with the aim of treating heart failure, its action on cell membranes and increased vagal tonus ${ }^{5}$ could contribute to reduce the onset of POAF.

It is known that the risk to develop $\mathrm{AF}$ in the postoperative of cardiac surgery may vary depending on the type of surgery. In a multicenter study, the risk of POAF was higher in patients who had undergone coronary artery bypass grafting combined with valvular surgery (OR: 1.8; CI 95\%: 1.2 - 2.7) or valve surgery alone (OR: 1.4; CI 95\%: 1.1 - 1.9) compared with coronary artery bypass grafting surgery alone. ${ }^{23}$ Although studies have associated the use of ECC with increased postoperative complications, among them, the occurrence of atrial fibrillation, ${ }^{24}$ this study did not find significant differences 
between the two groups. In addition, we did not observe any relation with the type of surgical procedure, nor in relation to the other intraoperative variables in the groups with and without POAF.

Several studies have demonstrated the association between arrhythmia and adverse postoperative outcomes. ${ }^{23,25}$ A meta-analysis ${ }^{23}$ with over 69 thousand patients showed that the length of stay was significantly higher among patients with and without POAF (11.0 vs 8.9 days, respectively; $p<0.00001)$. In coherence with the literature data, POAF patients, in this study, remained hospitalized for longer periods.

Nevertheless, mortality rates were higher among patients without POAF. These results were surprising, but some hypothesis can help us understand them. Short-term follow-up compared to other studies who had followed the patients after hospital discharge can contribute to decrease the number of new-onset and recurrent cases of POAF, as well as the number of deaths. In a meta-analysis, the recurrence rate of POAF ranged from $61 \%$ to $100 \%$ within two years. ${ }^{26}$

With respect to the estimation of the predictive capacity of the scores, the cut-off values of the CHADS and $\mathrm{CHA}_{2} \mathrm{DS}_{2} \mathrm{VASc}$ scores that best discriminated patients with and without POAF were $>0.5$ and $<3.5$, respectively. In other words, patients would be at risk of developing POAF even if they had relatively few risk factors. In this situation, it is possible that the scores would not be very useful for identifying patients that should receive more intensive monitoring in the postoperative period or other prophylactic measures. Corroborating that perspective, the sensitivity of the $\mathrm{CHADS}_{2}$ score increased, but specificity was extremely low; and for $\mathrm{CHA}_{2} \mathrm{DS}_{2} \mathrm{VASc}$, they remained far below adequate.

When assessing the effect of LA size on the predictive capacity of these scores, although the sensitivity of the $\mathrm{CHADS}_{2}$ score has decreased, all the other measures of specificity, PPV and NPV improved, but did not seem to be satisfactory. Similarly, for the $\mathrm{CHA}_{2} \mathrm{DS}_{2} \mathrm{VASc}$ score, in spite of a decrease in the specificity value, there was an improvement in all the other measures, which is not enough to ensure its adequacy.

Moreover, the regression models failed to show that the scores, alone or in association with the LA, are predictors of POAF. Therefore, it can be asserted that the models analyzed in this study are not good predictors of POAF. The literature is controversial regarding the determination of the predictive capacity of the $\mathrm{CHADS}_{2}$ and $\mathrm{CHA}_{2} \mathrm{DS}_{2}$ VASc scores. . $^{8,9,10,13}$

Some studies have shown that the risk of POAF increased as the $\mathrm{CHADS}_{2}$ and $\mathrm{CHA}_{2} \mathrm{DS}_{2} \mathrm{VASc}$ scores increased, but they did not demonstrate their predictive capacity. ${ }^{9,10}$ Recently, researchers ${ }^{13}$ have analyzed the predictive capcity of different risk scores (Society of Thoracic Surgeons risk of mortality score, Cohorts for Heart and Aging Research in Genomic Epidemiology (CHARGE)-AF score, POAF score and $\mathrm{CHA}_{2} \mathrm{DS}_{2} \mathrm{VASc}$ ) and age for the new- onset of AF after coronary artery bypass graft operation. They noted that none of the variables analyzed performed well. The ROC area for CHARGE-AF was 0.6796 (CI 95\%: 0.6672-0.6920), whereas for $\mathrm{CHA}_{2} \mathrm{DS}_{2} \mathrm{VASc}$ it was 0.5917 (CI 95\%: 0.57820.6052). Different results were obtained in another study, which showed good estimations on sensitivity (84.21), specificity (84.54) and negative predictive value (97.23) of the $\mathrm{CHA}_{2} \mathrm{DS}_{2} \mathrm{VASc}$ score to predict the risk of AF after coronary artery bypass, with a ROC area of 0.87 .

The present study has limitations relating to sample size and to the fact that this is a single-center study. Furthermore, the short follow-up period did not allow for the identification of new- onset and recurring AF after hospital discharge, which might have contributed to poor score performance in predicting arrhythmia, since the items of both scores take into account chronic conditions that can affect myocardial structure and stability in the long term after cardiac surgery.

\section{Conclusion}

The $\mathrm{CHADS}_{2}$ and $\mathrm{CHA}_{2} \mathrm{DS}_{2}$-VASc scores alone were not good predictors of POAF in patients undergoing coronary artery bypass graft and / or valvular surgery in this study. Although LA size has improved the estimation of sensitivity, specificity, PPV and NPV, it was not enough to improve the predictive capacity of the scores.

\section{Author contributions}

Conception and design of the research: Silva NA, Butcher RCGS. Acquisition of data: Silva NA. Analysis and interpretation of the data: Silva NA, Butcher RCGS. Statistical analysis: Silva NA, Butcher RCGS. Writing of the manuscript: Silva NA, Butcher RCGS. Critical revision of the manuscript for intellectual content: Silva NA, Butcher RCGS. 


\section{Potential Conflict of Interest}

No potential conflict of interest relevant to this article was reported.

\section{Sources of Funding}

There were no external funding sources for this study.

\section{References}

1. Zimerman LI, Fenelon G, Martinelli Filho M, Grupi C, Atié J, Lorga Filho A, et al. Diretrizes Brasileiras De Fibrilação Atrial. Arq Bras Cardiol. 2009;92(6 supl.1):1-39.

2. Justo FA, Silva AFG. Epidemiological aspects of atrial fibrillation. Rev Med. 2014;93(1):1-13.

3. Pivatto Júnior F, Teixeira Filho GF, Sant'anna JR, Py PM, Prates PR, Nesralla IA, et al. Advanced age and incidence of atrial fibrillation in the postoperative period of aortic valve replacement. Rev Bras Cir Cardiovasc. 2014;29(1):45-50.

4. Silva RG, Lima GG, Guerra N, Bigolin AV, Petersen LC. Risk index proposal to predict atrial fibrillation after cardiac surgery. Rev Bras Cir Cardiovasc. 2010;25(2):183-9.

5. Magalhães LP, Figueiredo MJO, Cintra FD, Saad EB, Kuniyishi RR, Teixeira RA, et al. II Diretrizes Brasileiras de Fibrilação Atrial. Arq Bras Cardiol. 2016;106(4 Supl. 2):1-22.

6. Mountantonakis SE, Grau-Sepulveda MV, Bhatt DL, Hernandez AF, Peterson ED, Fonarow GC. Presence of atrial fibrillation is independently associated with adverse outcomes in patients hospitalized with heart failure: an analysis of get with the guidelines - heart failure. Circ Heart Fail. 2012;5(2):191-201

7. Ha AC, Breithardt G, Camm AJ, Crijns HJ, Fitzmaurice GM, Kowey PR, et al. Health-related quality of life in patients with atrial fibrillation treated with rhythm control versus rate control: insights from a prospective international registry (Registry on Cardiac Rhythm Disorders Assessing the Control of Atrial Fibrillation: RECORD-AF). Circ Cardiovasc Qual Outcomes. 2014;7(6):896-904.

8. Borde D, Gandhe U, Hargave N, Pandey K, Mathew M, Joshi S. Prediction of postoperative atrial fibrillation after coronary artery bypass grafting surgery: is CHA2DS2VASc score useful? Ann Card Anaesth. 2014;17(3):182-7.

9. Chua SK, Shyu KG, Lu MJ, Lien LM, Lin CH, Chao HH, et al. Clinical utility of CHADS2 and CHA2DS2-VASc scoring systems for predicting postoperative atrial fibrillation after cardiac surgery. J Thorac Cardiovasc Surg. 2013;146(4):919-26.

10. Sareh S, Toppen W, Mukdad L, Satou N, Shemin R, Buch E, et al. CHADS2 score predicts atrial fibrillation following cardiac surgery. J Surg Res. 2014;190(2):407-12.

11. Kashani RG, Sareh S, Genovese B, Hershey C, Rezentes C, Shemin R, et al. Predicting postoperative atrial fibrillation using CHA2DS2-VASc scores. J Surg Res. 2015;198(2):267-72.

12. Gage BF, Waterman AD, Shannon W, Boechler M, Rich MW, Radford MJ. Validation of clinical classification schemes for predicting stroke: results from the National Registry of Atrial Fibrillation. JAMA. 2001;285(22):2864-70.

13. Pollock BD, Filardo G, Da Graca B, Phan TK, Ailawadi G, Thouran $\mathrm{V}$, et al. Predicting new-onset post-coronary artery bypass graft

\section{Study Association}

This study is not associated with any thesis or dissertation work.

\section{Ethics approval and consent to participate}

This article does not contain any studies with human participants or animals performed by any of the authors.

atrial fibrillation with existing risk scores. Ann Thorac Surg. 2018;105(1):115-21

14. Folla CO, Melo CC, Silva RC. Predictive factors of atrial fibrillation after coronary artery bypass grafting. Einstein (São Paulo). 2016;14(4):480-5.

15. Lip GY, Nieuwlaat R, Pisters R, Lane DA, Crijns HJ. Refining clinical risk stratification for predicting stroke and thromboembolism in atrial fibrillation using a novel risk factor-based approach: the euro heart survey on atrial fibrillation. Chest. 2010;137(2):263-72.

16. Gavino AI, McLachlan CS. Review of screening studies for atrial fibrillation in rural populations of 11 countries. Proc (Bayl Univ Med Cent). 2017;30(3):280-5.

17. Staerk L, Sherer JA, Ko D, Benjamin EJ, Helm RH. Atrial fibrillation: epidemiology, pathophysiology, and clinical Ooutcomes. Circ Res. 2017;120(9):1501-17.

18. Todorov H, Janssen I, Honndorf S, Bause D, Gottschalk A, Baasner S, et al. Clinical significance and risk factors for new onset and recurring atrial fibrillation following cardiac surgery-a retrospective data analysis. BMC Anesthesiol. 2017;17(1):163.

19. Gorczyca I, Michta K, Pietrzyk E, Wo $\square$ akowska-Kapłon B. Predictors of post-operative atrial fibrillation in patients undergoing isolated coronary artery bypass grafting. Kardiol Pol. 2018;76(1):195-201.

20. Camarozano A, Rabischoffsky A, Maciel BC, Brindeiro Filho D, Horowitz ES, Pena JLB, et al.,Sociedade Brasileira de Cardiologia. Diretrizes das indicações da ecocardiografia. Arq Bras Cardiol. 2009;93(6 supl. 3):e265-302.

21. Nascimento BC, Mesquita ET. Atrial fibrillation in heart failure: new advances in molecular genetics and treatment. Rev Bras Cardiol. 2010;23(1):25-34.

22. Geovanini GR, Alves RJ, Brito G, Miguel GA, Glauser VA, Nakiri K. Postoperative atrial fibrillation after cardiac surgery: who should receive chemoprophylaxis? Arq Bras Cardiol. 2009;92(4):326-30.

23. Akintoye E, Sellke F, Marchioli R, Tavazzi L, Mozaffarian D. Factors associated with postoperative atrial fibrillation and other adverse events after cardiac surgery. J Thorac Cardiovasc Surg. 2018;155(1):242-51.

24. Dieberg G, Smart NA, \& King N. On-vs. off-pump coronary artery bypass grafting: a systematic review and meta-analysis. Int J Cardiol. 2016 Nov 15;223:201-11.

25. Phan K, Ha HS, Phan S, Medi C, Thomas SP, Yan TD. New-onset atrial fibrillation following coronary bypass surgery predicts long-term mortality: a systematic review and meta-analysis. Eur J Cardiothorac Surg. 2015;48(6):817-24

26. Lowres N, Mulcahy G, Jin K, Gallagher R, Neubeck L, \& Freedman $B$. Incidence of postoperative atrial fibrillation recurrence in patients discharged in sinus rhythm after cardiac surgery: a systematic review and meta-analysis. Interact Cardiovasc Thorac Surg. 2018;26(3):115-21. 